\title{
Physiology of cold-acclimation in non-diapausing adults of Pyrrhocoris apterus (Heteroptera)
}

\author{
MARTin ŠLACHTA ${ }^{1}$, Petra BERKOVÁ ${ }^{1}$, JAN VAMBERA $^{2}$ and VLADiMír KOŠŤÁL ${ }^{1 *}$ \\ ${ }^{1}$ Institute of Entomology, Academy of Sciences of the Czech Republic, České Budějovice, Czech Republic \\ ${ }^{2}$ Faculty of Biology, University of South Bohemia, České Budějovice, Czech Republic
}

Key words. Cold hardiness, diapause, acclimation, supercooling, cryoprotectants, phospholipids

\begin{abstract}
Chill tolerance (time of survival at $-5^{\circ} \mathrm{C}$ ) increased in non-diapausing (reproducing) adults of Pyrrhocoris apterus after a gradual, 4-week-long decrease in ambient temperature from $25^{\circ}$ to $0^{\circ} \mathrm{C}$. The level of chill tolerance attained after cold-acclimation was considerably lower than that in similarly cold-acclimated diapausing adults. Some physiological changes accompanied the coldacclimation, irrespective of developmental state (diapause vs. reproduction). They were: A decreased oxygen consumption, loss of body water, an increased haemolymph osmolality, an increased proportion of phosphatidylethanolamines vs. a decreased proportion of phosphatidylcholines in membrane phospholipids, and an increased proportion of linoleic vs. a decreased proportion of oleic acid in phosphatidylethanolamines. Such changes could contribute to the limited potential for cold-acclimation found in non-diapausing insects. Other physiological changes appeared to require the induction of diapause prior to cold-acclimation. They were: Down regulation of ice nucleators resulting in a lowering of the individual supercooling point, synthesis and accumulation of specific "winter" polyols, an increased proportion of palmitic acid in membrane phospholipids; and regulation of the concentrations of $\mathrm{Na}^{+}$and $\mathrm{K}^{+}$in the haemolymph. The potential contributions of these changes to the cold hardiness of $P$. apterus are discussed.
\end{abstract}

\section{INTRODUCTION}

It is now accepted widely that mechanisms of insect cold hardiness are numerous, diverse, often speciesspecific and work in integration (Baust \& Rojas, 1985; Lee \& Denlinger, 1991; Danks, 1996; Sømme, 1999; 2000). There appear to be two basic directions for future experimental studies in this field: (a) an in-depth investigation into the mode of action and regulation of individual mechanisms and (b) comparative studies which may reveal how mechanisms of cold hardiness could evolve, how are they integrated with each other and with developmental programs (ontogeny, diapause), or with other traits that influence evolutionary success (synchronization of the life cycle with seasonal changes, drought resistance, etc.).

This paper contributes to a "(b)-type" study of diapause, overwintering and cold hardiness in the red firebug, Pyrrhocoris apterus (L.) (Heteroptera: Pyrrhocoridae). Brachypterous adults (to which this study is restricted) of $P$. apterus enter a faculative reproductive diapause in response to short-days, low temperature and high population density (Hodek, 1968, 1983) through the effects of these factors on the neurohumoral system (Sláma, 1964; Hodková, 1976). Diapausing adults overwinter in a supercooled state and do not tolerate freezing of their body fluids. Their mean supercooling point (SCP, approximately $-13^{\circ} \mathrm{C}$ ) is about $4^{\circ} \mathrm{C}$ lower than that of non-diapausing adults and may decrease further to a minimum of between $-16^{\circ}$ and $-21^{\circ} \mathrm{C}$ upon exposure to declining, but still relatively high, ambient temperatures above $5^{\circ} \mathrm{C}$ (Hodková \& Hodek, 1997; Košt'ál \& Šimek,
2000). The high chill tolerance, expressed as a capacity to survive at a sub-zero temperature $\left(-15^{\circ} \mathrm{C}\right)$ close to the minimum SCP for extended periods of time (up to 2 weeks), develops independently of SCP depression. It requires further cold-acclimation at ambient temperatures below $5^{\circ} \mathrm{C}$ and the accumulation of specific "winter" polyols (ribitol, sorbitol, mannitol, and arabinitol) (Koštál \& Šlachta, 2001; Koštál et al., 2001). In addition, the photoperiodic induction of diapause and/or exposure to low temperatures results in a restructuring of the phospholipid composition of the biological membranes of $P$. apterus, which may also contribute to cold hardiness (Hodková et al., 1999).

In this study we show that the level of chill tolerance is much lower in non-diapausing (reproducing) individuals of $P$. apterus than in diapausing individuals. Nevertheless, even the non-diapausing individuals are capable of cold-acclimation during a gradual, 4-weeklong decline in ambient temperatures to $0^{\circ} \mathrm{C}$. By comparing various physiological responses to declining temperature in diapausing and non-diapausing individuals we set out to: (1) evaluate the potential contribution of different physiological responses to chill tolerance and (2) distinguish between the responses triggered solely by changes in ambient temperature, and the responses requiring the synergistic effects of developmental program and temperature.

\section{MATERIALS AND METHODS}

\section{Insects and experimental conditions}

The red firebugs, $P$. apterus, were collected during the summer of 1999 in a field near České Budějovice, Czech

\footnotetext{
* Corresponding author. tel: +42038 7775229; fax: +42038 5300354; e-mail: kostal@entu.cas.cz
} 
Republic. Experimental insects came from a population which was reared in the laboratory for up to ten generations. The bugs were kept in conditions which promote continuous development, without reproductive diapause, i.e. a long day photoperiod (LD) of 18L: 6D and a constant temperature of $25^{\circ} \mathrm{C}$ (Hodek, 1968). The dry seeds of the linden tree (Tilia parviflora Ehrh.) as a food source and water were provided ad libitum

Experimental adults were maintained under the $\mathrm{LD} / 25^{\circ} \mathrm{C}$ conditions for approximately two weeks after moulting (at that time most females had already started to oviposit). These young adults served as a control group. Another group of 14-day-old adults was subjected to a gradual decrease in temperature (acclimation). The thermoperiod (cryophase coinciding with scotophase) was lowered weekly, in a step-wise manner: $20^{\circ} / 10^{\circ} \mathrm{C} \rightarrow$ $15^{\circ} / 5^{\circ} \mathrm{C} \rightarrow 10^{\circ} / 0^{\circ} \mathrm{C}$, with a constant temperature of $0^{\circ} \mathrm{C}$ for 1 week as the final step. The LD photoperiod was maintained until the temperature reached a constant $0^{\circ} \mathrm{C}$, at which time continuous darkness (DD) was applied. Mortality was low during acclimation $(<3 \%)$. Pre-oviposition period was observed in individual females to verify that the reproductive diapause was not induced during the temperature-decrease (Hodek, 1971).

The experiments were performed on five independent generations of $P$. apterus. As no significant differences were found between generations, the results were pooled with respect to the two treatments (control and cold-acclimated). The sexes were considered separately only where sexual differences were significant (fresh and dry weight, oxygen consumption).

All the measurements (as described below) that were taken from non-diapausing individuals were compared with data obtained for diapausing $P$. apterus in earlier studies (Sláma, 1964; Hodková \& Hodek, 1997; Šula et al., 1998; Hodková et al., 1999; Koštál et al., 2001). Some comparative parameters for diapausing individuals (oxygen consumption, fresh and dry weight, haemolymph osmolality and concentration of $\mathrm{Na}^{+}$and $\mathrm{K}^{+}$) were originally obtained in this study. Diapausing adults were obtained by rearing larvae at $25^{\circ} \mathrm{C}$ under a short-day photoperiod (SD) 12L: 12D (Hodek, 1968). The parameters were measured either in young diapausing adults (2-3 weeks old) or in cold-acclimated diapausing adults that were subjected to a similar gradual decrease in ambient temperature as described above.

\section{Cold hardiness}

The temperature of crystallization of body fluids (supercooling point, SCP) was measured at a cooling rate of $0.3 \% \mathrm{~min}$ according to the method of Nedverd et al. (1995).

Chill tolerance was measured as survival at $-5^{\circ} \mathrm{C}$ (a temperature well above the mean SCP). The parameter $L t 50.5(50 \%$ lethal time at a temperature of $-5^{\circ} \mathrm{C}$ ), which gives the time of exposure that is survived by $50 \%$ of population, was calculated using nonlinear logistic regression (software package Statistica 6.0, StatSoft). Typically, the experimental data were best fitted by a sigmoid curve (using the least squares loss function):

$$
S=L^{*}\left\{\exp \left[A *\left(1-t / L t 50_{-5}\right)\right]\right\} /\left\{1+\exp \left[A *\left(1-t / L t 50_{-5}\right)\right]\right\}
$$

where $S$ is the survival rate ( 0 to 1.0 ), L is the initial level of survival ( $y$ axis intercept), $A$ describes the slope of the middle part of the sigmoid curve, and $t$ is the time of exposure. Samples of 10 to 30 adults were exposed to temperatures of $-5^{\circ} \mathrm{C}$ (range $-4.5^{\circ}$ to $-5.2^{\circ} \mathrm{C}$ ) for various periods ( 1 to 28 days). The capacity for co-ordinated crawling at $\mathrm{LD} / 25^{\circ} \mathrm{C}$, seven days after the exposure, was used as the criterion for survival (prior to the transfer to $\mathrm{LD} / 25^{\circ} \mathrm{C}$, the bugs were kept at $+5^{\circ} \mathrm{C}$ for 2 hours)

\section{Oxygen consumption}

The oxygen consumption of individual adults was measured manometrically with a Warburg constant respirometer and using a $5 \% \mathrm{KOH}$ solution to absorb $\mathrm{CO}_{2}$. The measurement at $20^{\circ} \mathrm{C}$ was repeated 4 times for each individual (one measurement took ca 1 hour) and the mean was calculated. At $0^{\circ} \mathrm{C}$, the time needed for one measurement was about 6 hours and thus only one measurement was taken from each individual.

\section{Water content, haemolymph osmolality and concentration of} cations

The fresh weight (FW) of individual adult insects was measured on a Sartorius balance (sensitivity $0.1 \mathrm{mg}$ ). The dry weight (DW) was obtained after drying the specimens for 5 days at $60^{\circ} \mathrm{C}$. The water content (WC) was expressed as mg per mg of DW.

Haemolymph samples $(3-5 \mu 1)$ were collected from individual insects by cutting off one of the antennae and allowing it to bleed into a capillary tube. Osmolality was measured immediately in 10-15 $\mathrm{nl}$ haemolymph droplets using the Clifton Nanoliter Osmometer, according to the manufacturer's manual (Clifton Technical Physics, USA). Five to six droplets of haemolymph, taken from a single insect, were measured in parallel and a mean value was calculated. Each droplet was checked for the presence/absence of the thermal hysteresis phenomenon by observing the no-growth/growth of the last visible ice crystal (15-20 $\mu \mathrm{m}$ in diameter) after the decrease in temperature.

Concentrations of $\mathrm{Na}^{+}$and $\mathrm{K}^{+}$ions were determined from extracts of the haemolymph samples in $100 \mu \mathrm{l}$ of $1 \mathrm{M}$ solution of trichloroacetic acid (Sigma Chemical Co.) in deionized water (conductivity $<0.1 \mu \mathrm{S} / \mathrm{cm}$ ). After extraction, the samples were centrifuged at $20,000 \mathrm{~g}$ for $10 \mathrm{~min}$ and the concentrations of ions were measured in supernatants by atomic emission spectrophotometry $\left(\mathrm{Na}^{+}\right.$at $589.0 \mathrm{~nm} ; \mathrm{K}^{+}$at $\left.766.5 \mathrm{~nm}\right)$ using a spectrophotometer SpectrAA 640 (Varian Techtron, Australia).

\section{Biochemical analyses}

The concentrations of the four "winter" polyols (arabinitol, ribitol, mannitol and sorbitol), that typically accumulate in diapausing cold-acclimated $P$. apterus adults (Košt’ál \& Šimek, 2000 ), were measured in $70 \%$ ethanol extracts of the haemolymph samples. The extracts were centrifuged at $20,000 \mathrm{~g}$ for 10 min and the pooled supernatants from two replications of the procedure were used for o-methyloxime trimethylsilyl derivatization and subsequent analysis by gas chromatography, coupled to mass spectrometry (Košt'ál \& Simek, 1995).

Lipids were extracted from samples of the pro- and mesothoracic segments or the fat body (tissues from 10 individuals were pooled to obtain one sample) in ice-cold chloroform : methanol $(2: 1, \mathrm{v} / \mathrm{v})$ solution using the modified method of Folch et al. (1957). The individual lipid classes were separated by high performance thin-layer chromatography (HPTLC) and quantified by measuring the amount of phosphorus spectrophotometrically (Kostal \& Simek, 1998; Hodková et al., 1999). To identify the molecular species of the phospholipids and determine their relative weight proportions, the extracts were analyzed by electrospray ionization quadrupole ion trap mass spectrometry (ESI QITMS) on an LCQ mass spectrometer (Thermoquest, USA). The extracts were infused directly into an ESI chamber after injection of the sample via a $5 \mu$ loop into a stream of the mobile phase $(10 \mathrm{mM}$ methanolic ammonium formate, $50 \mu \mathrm{l} / \mathrm{min}$ ). Positive ESI/MS and $\mathrm{MS}^{2}$ and or $\mathrm{MS}^{3}$ spectra were recorded at $4.5 \mathrm{kV}$, with a capillary voltage of $8 \mathrm{~V}$ and a capillary temperature of $190^{\circ} \mathrm{C}$. The full scan mass spectra were acquired over a mass range of $\mathrm{m} / \mathrm{z} 700-900$ for general lipid 
TABLE 1. Mortality and oviposition in non-diapausing adult females of Pyrrhocoris apterus prior to, and after a gradual acclimation to $0^{\circ} \mathrm{C}$.

\begin{tabular}{|c|c|c|c|c|}
\hline \multirow{2}{*}{$\begin{array}{l}\text { Treatment, } \\
\text { temperature }\end{array}$} & \multicolumn{3}{|c|}{ Numbers (percentages) of females } & \multirow{2}{*}{$\begin{array}{c}\text { Number } \\
\text { of egg } \\
\text { batches } \\
\text { mean } \pm \\
\text { SE }\end{array}$} \\
\hline & total & died & & \\
\hline Control, $25^{\circ} \mathrm{C}$ & $48(100)$ & $13(27.1)$ & $43(89.6)$ & $4.1 \pm 0.3$ \\
\hline Acclimated & $28(100)$ & $19(67.9)$ & $19(67.9)$ & $2.5 \pm 0.4$ \\
\hline
\end{tabular}

Each female was kept with a single male. Mortality and oviposition were recorded for 25 days at $25^{\circ} \mathrm{C} / \mathrm{LD}$.

profiling. Headgroup composition was identified by means of positive $\mathrm{MS}^{2}$ spectra, due to a specific fragmentation of ions [M $+\mathrm{H}]^{+}$and/or $[\mathrm{M}+\mathrm{NH} 4]^{+}$corresponding to the loss of characteristic headgroups in dependence on the lipid class. Negative ESI spectra were recorded at $4.5 \mathrm{kV}$, with a capillary voltage of $-21.5 \mathrm{~V}$ and a capillary temperature of $190^{\circ} \mathrm{C}$. Type and position $(s n 1 / s n 2)$ of the fatty acid (FA) residues of each molecular species were determined, from the negative $\mathrm{MS}^{2}$ spectra, for the principal phospholipids revealed in the samples.

\section{RESULTS}

\section{Oviposition, mortality after cold-acclimation and oxygen consumption}

Most of the control females started oviposition within the first 2 weeeks of adulthood and, within the next 25 days at $\mathrm{LD} / 25^{\circ} \mathrm{C}, 27 \%$ of them died and almost $90 \%$ of them laid eggs with a characteristic interval of ca. 5 days between two successive egg-batches. Females that were subjected to a temperature decrease (acclimated) died within the next 25 days at $\mathrm{LD} / 25^{\circ} \mathrm{C}$ with a much higher frequency than the controls. Nevertheless, mating activity and regular oviposition occurred in $68 \%$ of these females (Table 1). These results confirmed that $P$. apterus adults did not enter diapause as a result of a temperature decrease.

Relatively high oxygen consumption rates, around 500 $\mu \mathrm{O}_{2} / \mathrm{h} / \mathrm{mg} \mathrm{FW}$, were found in control individuals at $20^{\circ} \mathrm{C}$. These rates decreased to about $30 \mu \mathrm{l} \mathrm{O} / \mathrm{h} / \mathrm{mg} \mathrm{FW}$ after a gradual acclimation to $0^{\circ} \mathrm{C}$ (Table 2).

The oxygen consumption rates at $20^{\circ} \mathrm{C}$ in diapausing 2-3 week-old males and females were $339.0 \pm 41.8 \mu 1$ $\mathrm{O}_{2} / \mathrm{h} / \mathrm{mg} \mathrm{FW}($ mean $\pm \mathrm{SE}, n=8$ ) or $277.5 \pm 30.9 \mu 1$ $\mathrm{O}_{2} / \mathrm{h} / \mathrm{mg} \mathrm{FW}(n=8)$, respectively. These oxygen consumption rates declined to $17.1 \pm 2.5 \mu \mathrm{O}_{2} / \mathrm{h} / \mathrm{mg} \mathrm{FW}(n=$ $8)$ and $8.4 \pm 0.8 \mu \mathrm{l} \mathrm{O} / \mathrm{h} / \mathrm{mg} \mathrm{FW}(n=8)$ after a gradual acclimation to $0^{\circ} \mathrm{C}$. Oxygen consumption rates were significantly lower $(P<0.05$, t-test $)$ in diapausing indi-

TABLE 2. Oxygen consumption in non-diapausing adults of Pyrrhocoris apterus prior to, and after a gradual acclimation to $0^{\circ} \mathrm{C}$.

\begin{tabular}{lcc}
\hline $\begin{array}{l}\text { Treatment, } \\
\text { temperature }\end{array}$ & \multicolumn{2}{c}{ Oxygen consumption $\left[\mu 1 \mathrm{O}_{2} / \mathrm{h} / \mathrm{g} \mathrm{FW}\right]$} \\
\cline { 2 - 3 } & Males mean $\pm \mathrm{SE}(n)$ & Females mean $\pm \mathrm{SE}(n)$ \\
\hline Control, $20^{\circ} \mathrm{C}$ & $485.1 \pm 44.0(12)$ & $527.4 \pm 41.5(13)$ \\
Acclimated & $37.0 \pm 4.7(8)$ & $23.3 \pm 3.0(8)$ \\
t-test, $P$ & $<0.0001^{* * *}$ & $<0.0001^{* * *}$ \\
\hline
\end{tabular}

TABLE 3. Supercooling points (SCP) of non-diapausing adults of Pyrrhocoris apterus prior to, and after a gradual acclimation to $0^{\circ} \mathrm{C}$.

\begin{tabular}{lcrc}
\hline Treatment, temperature & $n$ & \multicolumn{2}{c}{$S C P\left[{ }^{\circ} \mathrm{C}\right]$} \\
\cline { 2 - 4 } & & mean $\pm \mathrm{SE}$ & range \\
\hline Control, $25^{\circ} \mathrm{C}$ & 154 & $-9.4 \pm 0.4$ & -4.4 to -15.4 \\
Acclimated & 93 & $-10.3 \pm 0.4$ & -4.1 to -14.3 \\
t-test, $P$ & \multicolumn{3}{|c}{$0.0007^{* * * *}$} \\
\hline
\end{tabular}

viduals than in non-diapausing individuals (both males and females) at both temperatures $\left(20\right.$ and $\left.0^{\circ} \mathrm{C}\right)$.

\section{Cold hardiness}

The mean SCP of the control adults was $-9.4^{\circ} \mathrm{C}$. A gradual acclimation to $0^{\circ} \mathrm{C}$ resulted in a very moderate (but statistically significant) depression of the mean SCP by ca. $1^{\circ} \mathrm{C}$ (Table 3 ). The majority of individual SCP values $\left(243\right.$ out of a total 247 ) were lower than $-5^{\circ} \mathrm{C}$, which justifies the use of the exposure to $-5^{\circ} \mathrm{C}$ for estimating chill tolerance (with minimal mortality from spontaneous freezing).

The reduction in fitness as a result of a gradual acclimation to $0^{\circ} \mathrm{C}$ must be taken into account when evaluating chill tolerance. This "negative" effect is supported by the survival data summarized in Table 1 , and is also reflected in the decrease of parameter $L$ of the sigmoid survival curve (Table 4). As is evident from Fig. 1, approximately one half of $P$. apterus (of both sexes) responded "positively" to the temperature decrease, surviving at $-5^{\circ} \mathrm{C}$ for longer periods than the controls ( $L t 50_{-5}$ extended from 7.8 to 14.7 days), and were thus considered to be coldacclimated. However, lower survival was observed in acclimated than in control groups after relatively short exposures (1-7 days) to $-5^{\circ} \mathrm{C}$. We interpret it as a sign of decreased fitness in a certain part of the sample during acclimation to $0^{\circ} \mathrm{C}$

\section{Water content, haemolymph osmolality and cations}

While dry weight was unaffected, relative water content decreased significantly in non-diapausing males and females during the gradual acclimation to $0^{\circ} \mathrm{C}$. On average, males lost $11.0 \%$ and females $8.7 \%$ of their total body water. Haemolymph osmolality increased during the acclimation by $111.8 \mathrm{mOsm} / \mathrm{kg}$ (i.e. by $30.3 \%$ ). Haemolymph concentrations of the two cations, $\mathrm{Na}^{+}$and $\mathrm{K}^{+}$, increased approximately two-fold (Table 5).

In diapausing individuals, the dry weight was unaffected, but males lost 5.2\% and females $12.6 \%$ of their total body water during a gradual acclimation to $0^{\circ} \mathrm{C}$ [(water content in males: $1.34 \pm 0.03 \mathrm{mg} / \mathrm{mg} \mathrm{DW}$ (mean \pm $\mathrm{SE}, n=19)$ before and $1.27 \pm 0.04 \mathrm{mg} / \mathrm{mg} \mathrm{DW}(n=14)$ after acclimation, in females: $1.26 \pm 0.03(n=14)$ and $1.10 \pm 0.03 \mathrm{mg} / \mathrm{mg} \mathrm{DW}(n=19)]$. Haemolymph osmolality in diapausing individuals was $422.1 \pm 6.0 \mathrm{mOsm} / \mathrm{kg}$ (mean $\pm \mathrm{SE}, n=6$ ) before, and $612.5 \pm 25.7 \mathrm{mOsm} / \mathrm{kg}(n$ $=6$ ) after gradual acclimation to $0^{\circ} \mathrm{C}$. Haemolymph concentrations of $\mathrm{Na}^{+}$and $\mathrm{K}^{+}$dropped moderately, but significantly $(P<0.05$; t-test), during cold acclimation of diapausing individuals $\left[\mathrm{Na}^{+}: 21.9 \pm 1.6 \mathrm{mM}\right.$ before and 
TABLE 4. Parameters of the sigmoid survival curves constructed for non-diapausing adults of Pyrrhocoris apterus exposed to $-5^{\circ} \mathrm{C}$ prior to, and after a gradual acclimation $0^{\circ} \mathrm{C}$.

\begin{tabular}{lcccc}
\hline Treatment, temperature & $n^{1}$ & $\begin{array}{c}L \\
\text { mean } \pm \text { SE }\end{array}$ & $\begin{array}{c}L t 50_{-5} \\
\text { mean } \pm \text { SE }\end{array}$ & $\begin{array}{c}\text { Proportion of variance } \\
\text { explained by sigmoid } \\
\text { curve [\%] }\end{array}$ \\
\hline Control, $25^{\circ} \mathrm{C}$ & 788 & $0.89 \pm 0.12$ & $7.8 \pm 0.9$ & 71 \\
Acclimated & 537 & $0.58 \pm 0.08$ & $14.7 \pm 1.8$ & 77 \\
t-test, $P$ & & $<0.001^{* * *}$ & $0.0003^{* * *}$ & \\
\hline
\end{tabular}

${ }^{1} n$ shows the total number of adults in the experiment, degrees of freedom for calculation of the two-tailed t-test were derived from the number of true replications (i.e. groups of $10-30$ adults exposed to $-5^{\circ} \mathrm{C}$ for various periods; $n=35$, control; $n=23$, acclimated).

$16.3 \pm 1.2 \mathrm{mM}$ after gradual acclimation to $0^{\circ} \mathrm{C} ; \mathrm{K}^{+}: 16.3$ $\pm 1.0 \mathrm{mM}$ before and $11.1 \pm 3.4 \mathrm{mM}$ after (means $\pm \mathrm{SE}, n$ $=10)]$.

\section{Polyols}

The mean haemolymph concentrations of the four "winter" polyols (ribitol, sorbitol, arabinitol and mannitol) were relatively low, ranging between 0.15 and $0.42 \mathrm{mM}$ in all samples and no statistically significant changes were observed after a gradual acclimation to $0^{\circ} \mathrm{C}$ (data not shown).

\section{Phospholipids}

Phosphatidylethanolamines (PEs) together with phosphatidylcholines (PCs) made up more than $80 \%$ (molar) of all phospholipids in the muscle and fat body tissues. Seven molecular species dominated in the PEs and PCs from all samples. These were [fatty acid (FA) residues in positions $\operatorname{sn} 1 / \mathrm{sn} 2$ shown]:

$$
\begin{aligned}
& 16: 0 / 18: 2 \mathrm{n}-6 \\
& 16: 0 / 18: 1 \mathrm{n}-9 \\
& 18: 2 \mathrm{n}-6 / 18: 2 \mathrm{n}-6 \\
& 18: 1 \mathrm{n}-9 / 18: 2 \mathrm{n}-6 \\
& 18: 0 / 18: 2 \mathrm{n}-6 \\
& 18: 0 / 18: 1 \mathrm{n}-9 \\
& 18: 0 / 18: 0
\end{aligned}
$$

where $18: 2 n-6$ is linoleic acid; $18: 1 n-9$ is oleic acid; $16: 0$ is palmitic acid; and 18:0 is stearic acid.

The proportions of the individual molecular species of phospholipids changed only moderately during a gradual acclimation to $0^{\circ} \mathrm{C}$. The patterns of the changes were specific for each lipid class (PEs or PCs) and tissue. Thus, significant increases of PC $18: 1 n-9 / 18: 2 n-6$, countered by decreases of PC 16:0/18:2n-6, were found in both muscle and fat body tissues. PE 18:0/18:1n-9 and PE 16:0/18:1n-9 decreased in muscle and fat body tissues. PE 16:0/18:2n-6 increased in muscle and fat body tissues. PE 18:1n-9/18:2n-6 and PE 18:0/18:2n-6 increased in the fat body, and PE 18:0/18:0 decreased in the fat body. Such minor changes (each occurring by a magnitude of a few percent) were reflected in changes in the values of four calculated parameters (Table 6): (a) the relative proportion of PEs increased, while the proportion of PCs decreased, in both tissues (the changes in muscle PEs were statistically insignificant), (b) the unsaturation coefficient UFA/SFA did not change significantly, (c) the ratio of linoleic/oleic acid increased in PEs and decreased in PCs in both tissues, the change in fat body PC being insignificant, and (d) the proportion of 16:0 FA did not change significantly.

\section{DISCUSSION}

This paper shows that non-diapausing adult $P$. apterus can, to a limited extent, become cold-acclimated. Their chill tolerance increased in response to a gradual, 4-weeklong decrease in ambient temperature from 25 to $0^{\circ} \mathrm{C}$. The "limited extent" of cold-acclimation means that, (1) chill tolerance increased in approximately $50 \%$ of the population and (2) the level of chill tolerance achieved by non-diapausing adults $\left(L t 50_{-5}=14.7\right.$ days $)$ was lower than that achieved by comparable diapausing adults. Diapausing $P$. apterus had $L t 50_{-5}$ an equal to 28.6 days prior to, and $L t 50_{-5}$ greater than 50 days, after cold-acclimation using a similar temperature-protocol (Koštál et al., 2001). Two aspects that play important roles in the coldacclimation of diapausing adults of $P$. apterus were found to be completely missing in the non-diapausing adults. These were: (a) a down-regulation of ice nucleators resulting in SCP depression, and (b) an accumulation of

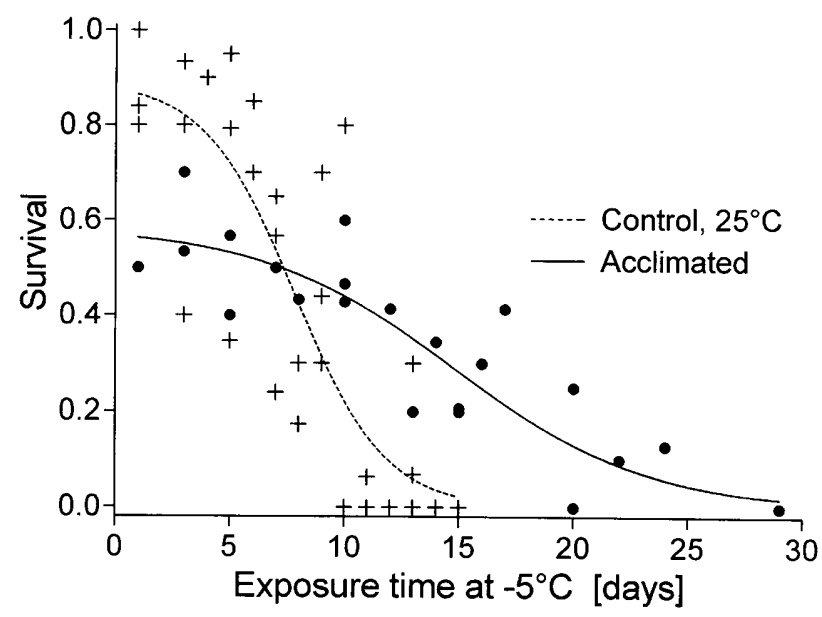

Fig. 1. Chill tolerance of non-diapausing adults of Pyrrhocoris apterus measured as their survival after exposure to $-5^{\circ} \mathrm{C}$ for different time periods. Acclimated adults $(n=537,23$ groups) were exposed to a 4-week-long gradual decrease of temperatures from 25 to $0^{\circ} \mathrm{C}$ prior to the test of chill tolerance. Reproducing 14-day-old adults ( $n=788,35$ groups) reared at $25^{\circ} \mathrm{C}$ served as a control. The experimental data were fitted with sigmoid curves as described in the Materials and Methods. The parameters of the curves are summarized in Table 4. 
TABLE 5. Dry weight, relative water content, haemolymph osmolality and concentrations of $\mathrm{Na}^{+}$and $\mathrm{K}^{+}$ions in non-diapausing adults of Pyrrhocoris apterus prior to, and after a gradual acclimation to $0^{\circ} \mathrm{C}$.

\begin{tabular}{|c|c|c|c|c|c|c|c|}
\hline \multirow{2}{*}{$\begin{array}{l}\text { Treatment, } \\
\text { temperature }\end{array}$} & \multicolumn{2}{|c|}{ Dry weight $[\mathrm{mg}]$} & \multicolumn{2}{|c|}{ Water content $[\mathrm{mg} / \mathrm{mgDW}]$} & \multirow{2}{*}{$\begin{array}{c}\text { Haemolypmh } \\
\text { osmolality } \\
{[\mathrm{mOsm} / \mathrm{kg}]}\end{array}$} & \multicolumn{2}{|c|}{ Concentration of ions $[\mathrm{mM}]$} \\
\hline & Males & Females & Males & Females & & $\mathrm{Na}^{+}$ & $\mathrm{K}^{+}$ \\
\hline Control, $25^{\circ} \mathrm{C}$ & $15.7 \pm 0.5(20)$ & $25.7 \pm 1.1(20)$ & $1.81 \pm 0.06(20)$ & $1.72 \pm 0.03(20)$ & $369.5 \pm 4.3(5)$ & $23.0 \pm 1.8(10)$ & $12.8 \pm 0.8(10)$ \\
\hline Acclimated & $15.1 \pm 0.6(20)$ & $22.7 \pm 1.0(14)$ & $1.61 \pm 0.04(20)$ & $1.57 \pm 0.21(14)$ & $481.3 \pm 23.7(5)$ & $49.2 \pm 12.9(10)$ & $21.5 \pm 3.6(10)$ \\
\hline t-test. $P$ & $0.4480 \mathrm{~ns}$ & $0.0638 \mathrm{~ns}$ & $0.0046^{* *}$ & $0.0176^{*}$ & $0.0009 * * *$ & $0.0602 \mathrm{~ns}$ & $0.0193^{*}$ \\
\hline
\end{tabular}

All results are shown as: mean $\pm \mathrm{SE}(n)$.

"winter" polyols (ribitol, sorbitol, arabinitol, and mannitol).

Diapausing $P$. apterus have a relatively low mean $S C P$ of $-13^{\circ} \mathrm{C}$ even at a high temperature of $20^{\circ} \mathrm{C}$. Coldacclimation decreases the $S C P$ to between -16 and $-21^{\circ} \mathrm{C}$ (Hodková \& Hodek, 1997; Košt'ál et al., 2001). A moderate decrease in $S C P$ by ca. $1^{\circ} \mathrm{C}$ was observed in the non-diapausing individuals of $P$. apterus used in this study, which probably had a negligible influence on the chill tolerance measured at $-5^{\circ} \mathrm{C}$ (i.e. considerably above the mean $S C P$ ).

Polyols are derived usually from glycogen reserves in overwintering insects (Storey \& Storey, 1991). Two-week old diapausing $P$. apterus adults (at $26^{\circ} \mathrm{C}$ ) have accumulated an average of $0.36 \mathrm{mg}$ of glycogen in their fat body (Šula et al., 1998). Such an amount corresponds, approximately, to the maximum total amount of "winter" polyols found in overwintering adults (ca. $0.4 \mathrm{mg}$; Koštál \& Šimek, 2000). Two-week old non-diapausing adults retain only ca $0.08 \mathrm{mg}$ of glycogen in their fat body (Š́ula et al., 1998), and no polyols were accumulated with decreasing temperature (this study). Thus, the resource for polyol biosynthesis (glycogen) and/or the biosynthetic capacity (enzymatic complement) appear to be insufficient for, or incapable of, the synthesis of "winter" polyols in nondiapausing $P$. apterus.

So, which are the mechanisms that could explain coldacclimation in non-diapausing individuals of $P$. apterus? In the following discussion, we deal with the potential roles of metabolic suppression, water and ionic balances, and the restructuring of biological membranes.

Pullin et al. (1991) suggested that the diapausemediated "suppression of some metabolic pathways in advance of low temperature exposure may prevent the damaging imbalance which may occur when enzyme activities change relative to each other as temperature decreases". In P. apterus, diapausing insects close down the processes of oogenesis, mating and oviposition (Hodek, 1968). Locomotion, food consumption and digestion also decrease substantially within the first few weeks of diapause development (Socha et al., 1997). As a result, the overall oxygen consumption rates at $20^{\circ} \mathrm{C}$ of diapausing adults are about half those of non-diapausing adults (Sláma, 1964; this study). The decrease in ambient temperature from $20^{\circ}$ to $0^{\circ} \mathrm{C}$ caused a further depression in metabolism to levels that were 13 or 23 times lower in non-diapausing individuals, and 20 or 33 times lower in diapausing individuals (the higher quotients apply for females). So that, at $0^{\circ} \mathrm{C}$, the metabolic rates were approximately 2 to 3 times lower in diapausing than in non-diapausing $P$. apterus adults. It remains to be demonstrated experimentally whether such a difference could affect chill tolerance.

Overwintering insects commonly reduce their water content and, in some cases, this has been interpreted as conferring increased cold hardiness by increasing the concentration of solutes (Ring \& Danks, 1994; Block, 1996). P. apterus overwintering in the field lose some $10-15 \%$ of body water between September and January (Koštál \& Šimek, 2000). In this study, the loss of 9-11\% of total body water after a cold-acclimation was observed in non-diapausing adults. The haemolymph osmolality increased concomitantly by $30 \%$ and the concentrations of $\mathrm{Na}^{+}$and $\mathrm{K}^{+}$doubled. In our parallel experiments with diapausing laboratory adults of $P$. apterus, we found that during cold-acclimation they: (a) lost $5-13 \%$ of total body water, similar to non-diapausing adults, (b) increased the osmolality of their haemolymph by 190.4 $\mathrm{mOsm} / \mathrm{kg}$ (i.e. by $45.1 \%$ ) [part of the increase (up to 100 $\mathrm{mOsm} / \mathrm{kg}$ ) can be ascribed to the accumulation of polyols, which was not observed in non-diapausing adults] and, (c) in contrast to non-diapausing individuals, decreased concentrations of $\mathrm{Na}^{+}$and $\mathrm{K}^{+}$in haemolymph, although only moderately. There is no indication that the water loss could have any adaptive meaning with respect to chill tolerance in $P$. apterus. The increases in haemolymph osmolality, which were higher than those that would be expected from the total body water loss, indicated that water might be lost preferentially from the haemolymph in both non-diapausing and diapausing individuals. Such a preferential loss of water could help to protect cells from excessive dehydration (Hadley, 1994) The difference found between non-diapausing and diapausing adults in their capacity to regulate the concentrations of $\mathrm{Na}^{+}$and $\mathrm{K}^{+}$in the haemolymph, during temperature decreases and loss of water, merits further study.

The restructuring of membrane lipids in response to a decrease in ambient temperature has been shown to enhance cold hardiness in different poikilothermic organisms (Cossins, 1994; Hazel, 1995). Pyrrhocoris apterus that were overwintering in the field responded to a seasonal decrease in ambient temperatures between August and January by (a) increasing the proportion of phosphatidylethanolamines (PEs) and decreasing the proportion of phosphatidylcholines (PCs), and (b) increasing the proportion of palmitic (16:0) acid and decreasing the propor- 
TABLE 6 Composition of phospholipids in muscle (A) and fat body (B) tissues of non-diapausing adults of Pyrrhocoris apterus prior to, and after a gradual acclimation to $0^{\circ} \mathrm{C}$.

\begin{tabular}{|c|c|c|c|c|c|c|c|c|}
\hline \multicolumn{9}{|l|}{ (A) Muscle } \\
\hline \multirow[t]{2}{*}{$\begin{array}{l}\text { Treatment, } \\
\text { temperature }\end{array}$} & \multicolumn{2}{|c|}{ Proportion of total PLs ${ }^{(1)}$} & \multicolumn{2}{|c|}{$\begin{array}{c}\text { Unsaturation coeff. } \\
\text { UFA/SFA }^{(2)}\end{array}$} & \multicolumn{2}{|c|}{ Ratio $18: 2 n-6 / 18: 1 n-9^{(2)}$} & \multicolumn{2}{|c|}{ Proportion of $16: 0^{(2)}$} \\
\hline & PEs & $\mathrm{PCs}$ & PEs & $\mathrm{PCs}$ & PEs & $\mathrm{PCs}$ & PEs & $\mathrm{PCs}$ \\
\hline Control, $25^{\circ} \mathrm{C}$ & $42.1 \pm 0.6$ & $41.8 \pm 0.2$ & $1.73 \pm 0.07$ & $4.15 \pm 0.12$ & $3.27 \pm 0.21$ & $5.61 \pm 0.28$ & $11.9 \pm 0.7$ & $9.7 \pm 0.9$ \\
\hline Acclimated & $43.7 \pm 0.7$ & $38.2 \pm 0.6$ & $1.80 \pm 0.11$ & $4.20 \pm 0.17$ & $4.42 \pm 0.12$ & $4.73 \pm 0.10$ & $11.7 \pm 0.2$ & $8.9 \pm 1.1$ \\
\hline t-test, $P$ & $0.1333 \mathrm{~ns}$ & $0.0014 * *$ & $0.6107 \mathrm{~ns}$ & $0.8181 \mathrm{~ns}$ & $0.0031 * *$ & $0.0253 *$ & $0.7927 \mathrm{~ns}$ & $0.5939 \mathrm{~ns}$ \\
\hline \multicolumn{9}{|l|}{ (B) Fat body } \\
\hline \multirow[t]{2}{*}{$\begin{array}{l}\text { Treatment, } \\
\text { temperature }\end{array}$} & \multicolumn{2}{|c|}{ Proportion of total PLs ${ }^{(1)}$} & \multicolumn{2}{|c|}{$\begin{array}{c}\text { Unsaturation coeff. } \\
\text { UFA/SFA }^{(2)}\end{array}$} & \multicolumn{2}{|c|}{ Ratio $18: 2 n-6 / 18: 1 n-9^{(2)}$} & \multicolumn{2}{|c|}{ Proportion of $16: 0^{(2)}$} \\
\hline & PEs & $\mathrm{PCs}$ & PEs & PCs & PEs & $\mathrm{PCs}$ & PEs & $\mathrm{PCs}$ \\
\hline Control, $25^{\circ} \mathrm{C}$ & $35.1 \pm 0.7$ & $47.7 \pm 0.6$ & $1.41 \pm 0.13$ & $3.16 \pm 0.24$ & $2.74 \pm 0.05$ & $3.32 \pm 0.21$ & $14.5 \pm 1.2$ & $8.7 \pm 0.4$ \\
\hline Acclimated & $42.9 \pm 1.5$ & $41.3 \pm 0.6$ & $1.50 \pm 0.03$ & $3.71 \pm 0.31$ & $3.94 \pm 0.11$ & $3.06 \pm 0.09$ & $14.2 \pm 0.3$ & $7.4 \pm 0.5$ \\
\hline t-test, $P$ & $0.0032 * *$ & $0.0010 * * *$ & $0.5251 \mathrm{~ns}$ & $0.2102 \mathrm{~ns}$ & $<0.0001 * * *$ & $0.2985 \mathrm{~ns}$ & $0.8164 \mathrm{~ns}$ & $0.0886 \mathrm{~ns}$ \\
\hline
\end{tabular}

${ }^{(1)}$ molar \%; ${ }^{(2)}$ weight \%.

All results are shown as mean \pm SE of $n=4$ tissue samples, 10 pooled specimens each.

Pls - phospholipids; Pes - phosphatidylethanolamines; PCs - phosphatidylcholines; UFA - unsaturated fatty acids; SFA - saturated fatty acids.

tion of 18-carbon fatty acids (Hodková et al., 1999). In the present study, the type-(a) response, but not the type-(b) response, was found in the thoracic muscles and fat body of non-diapausing individuals. The membranes of cold-acclimated poikilotherms generally contain higher proportions of PEs which is interpreted as conferring higher cold tolerance (Hazel, 1995). Although the changes in the proportions of PEs and PCs were similar in laboratory non-diapausing adults (this study) and in field diapausing adults (Hodková et al., 1999), the extent of the PEs increase was twice as high in field adults. In diapausing P. apterus, the proportion of palmitic acid increased significantly from 15 to $17-19 \%$ in muscle phospholipids between August and January (Hodková et al., 1999) and such a change was interpreted as conferring potentially greater thermotolerance by extending the range of temperatures at which the membranes remain fluid (Lewis et al., 1989; Ohtsu et al., 1998; Hodková et al., 1999). No similar change was found in nondiapausing adults in the present study. Fatty acid desaturation in response to decreasing ambient temperature is a recurring topic in many studies on cold-acclimation in different poikilotherms (Sinensky, 1974; Murata \& Wada, 1995; Tanaka et al., 1996; Aguillar et al., 1999), including insects (Bennet at al., 1997; Kostal \& Simek, 1998; Ohtsu et al., 1998). Nevertheless, no change was observed in the unsaturation coefficient after coldacclimation either in non-diapausing (this study) or in diapausing P. apterus (Hodková et. al., 1999). Ohtsu et al. (1998) hypothesized that increased cold tolerance in different Drosophila species is related to the presence of relatively higher proportions of mono-unsaturated and lower proportions of di-unsaturated fatty acids in phospholipids. Although a trend supporting such a hypothesis was weakly indicated in the PCs, the opposite response to cold-acclimation was observed in the PEs of $P$. apterus in this study and in a field population (Hodková et al., 1999).

In conclusion, some physiological changes found in $P$. apterus adults in response to the decrease in ambient temperature occurred irrespective of developmental program (diapause vs. reproduction). These were: (a) decreased oxygen consumption, (b) loss of body water, (c) increased haemolymph osmolality, (d) increased proportions of PEs vs. decreased proportion of PCs in membrane phospholipids, and (e) increased proportions of linoleic vs. decreased proportions of oleic acid in PEs. Such changes could contribute to a limited potential for cold-acclimation found in reproducing, non-diapausing individuals. Other physiological changes require induction of diapause prior to a decrease in ambient temperature. These were: (a) down regulation of ice nucleators resulting in a lowering of the $S C P$, (b) accumulation of specific "winter" polyols, (c) regulation of concentrations of $\mathrm{Na}^{+}$and $\mathrm{K}^{+}$in the haemolymph, and (d) an increased proportion of palmitic acid (16:0) in the membrane phospholipids. The two changes listed first were shown previously to enhance cold hardiness in P. apterus (Hodková \& Hodek, 1997; Košt'ál et al., 2001). The potential adaptive values of the ionic regulation and the proportion of palmitic acid in phospholipids remain to be tested.

ACKNOWLEDGEMENTS. We thank to Irena Vacková, Jana Mikešová and Marie Texlová for technical assistance. The concentrations of $\mathrm{Na}^{+}$and $\mathbf{K}^{+}$were measured by Jan Bastl (University of South Bohemia, České Budějovice). The study was supported by the Grant Agency of the Czech Republic (Grant 206/00/0946) and by the Academy of Sciences of the Czech Republic (project No. Z5007907).

\section{REFERENCES}

Aguillar P.S., Lopez P. \& de Mendoza D. 1999: Transcriptional control of the low-temperature-inducible des gene, encoding 
the (5 desaturase of Bacilus subtilis. J. Bacteriol. 181: $7028-7033$

BAUST J.G. \& RoJAS R.R. 1985: Insect cold hardiness: facts and fancy. J. Insect Physiol. 31: 755-759.

Bennett V.A., Pruitt N.L. \& Lee R.E.Jr. 1997: Seasonal changes in fatty acid composition associated with coldhardening in third instar larvae of Eurosta solidaginis. $J$. Comp. Physiol. B 167: 249-255.

BLOCK W. 1996: Cold or drought - the lesser of two evils for terrestrial arthropods? Eur. J. Entomol. 93: 325-339.

Cossins A.R. (ed.) 1994: Temperature Adaptation of Biological Membranes. Portland Press, London \& Chapel Hill.

Danks H.V. 1996: The wider integration of studies on insect cold-hardiness. Eur. J. Entomol. 3: 383-403.

Folch J., Lees M. \& Sloane Stanley G.H. 1957: A simple method for the isolation and purification of total lipids from animal tissues. J. Biol. Chem. 226: 497-509.

HADLEY N.F. 1994: Water Relations of Terrestrial Arthropods. Academic Press, San Diego, 356 p.

HAzEL J.R. 1995: Thermal adaptation in biological membranes: Is homeoviscous adaptation the explanation? Annu. Rev. Physiol. 57: 19-42.

HoDEK I. 1968: Diapause in females of Pyrrhocoris apterus L. (Heteroptera). Acta Entomol. Bohemoslov. 65: 422-435.

HoDEK I. 1971: Termination of adult diapause in Pyrrhocoris apterus (Heteroptera: Pyrrhocoridae) in the field. Entomol. Exp. Appl. 14: 212-222.

HODEK I. 1983: Role of environmental factors and endogenous mechanisms in the seasonality of reproduction in insects diapausing as adults. pp. 9-33. In: Diapause and Life Cycle Strategies in Insects. Brown V. K. \& Hodek I. (eds), Dr. W. Junk Publishers, The Hague, Boston, London.

HoDKová M. 1976: Nervous inhibition of corpora allata by photoperiod in Pyrrhocoris apterus. Nature 263: 521-523.

HoDKOvÁ M. \& HoDEK I. 1997: Temperature regulation of supercooling and gut nucleation in relation to diapause of Pyrrhocoris apterus (L.) (Heteroptera). Cryobiology 34: $70-79$.

Hodková M., Šrmek P., ZahradníčKová H. \& Nováková O. 1999: Seasonal changes in the phospholipid composition in thoracic muscles of a heteropteran, Pyrrhocoris apterus. Insect Biochem. Mol. Biol. 29: 367-386.

Košt'ÁL V. \& ŠIMEK P. 1995: Dynamics of cold hardiness, supercooling and cryoprotectants in diapausing and non-diapausing pupae of the cabbage root fly, Delia radicum L. J. Insect Physiol. 41: 627-634.

Kostal V. \& SimeK P. 1998: Changes in fatty acid composition of phospholipids and triacylglycerols after cold-acclimation of an aestivating insect prepupa. J. Comp. Physiol. B 168 : $453-460$

Košt'ÁL V. \& ŠIMEK P. 2000: Overwintering strategy in Pyrrhocoris apterus (Heteroptera): the relations between life-cycle, chill tolerance and physiological adjustments. J. Insect Physiol. 46: 1321-1329.

Košt'Ál V. \& Šlachta M. 2001: Variation in cold hardiness during overwintering of Pyrrhocoris apterus (Insecta: Heteroptera). Acta Soc. Zool. Bohem. in press.
Košt'Ál V., ŠLachta M. \& ŠimeK P. 2001: Cryoprotective role of polyols independent of the increase in supercooling capacity in diapausing adults of Pyrrhocoris apterus (Heteroptera: Insecta). Comp. Biochem. Physiol. B 130: 365-374.

Lee R.E.Jr. \& Dentinger D.L. (eds) 1991: Insects at Low Temperature. Chapman \& Hall, New York and London, 513 p.

LEWIS R.N.A.H., ManNock D.A. \& McElhaney R.N. 1989: Effect of fatty acyl chain length and structure of the lamellar gel to liquid-crystalline and lamellar to reversed hexagonal phase transition of aqueous phosphatidylethanolamine dispersions. Biochem. 28: 541-548.

Murata N. \& WADA H. 1995: Acyl-lipid desaturases and their importance in the tolerance and acclimatization to cold of cyanobacteria. Biochem. J. 308: 1-8.

Nedvěd O., Hodková M., BrunNhofer V. \& Hodek I. 1995: Simultaneous measurement of low temperature survival and supercooling in a sample of insects. Cryo-Letters 16: $108-113$.

Ohtsu T., Kimura M.T. \& Katagiri C. 1998: How Drosophila species acquire cold tolerance. Qualitative changes in phospholipids. Eur. J. Biochem. 252: 608-611.

Pullin A.S., Bale J.S. \& Fontaine X.L.R. 1991: Physiological aspects of diapause and cold tolerance during overwintering in Pieris brassicae. Physiol. Entomol. 16: 447-456.

RiNG R.A. \& DANKS H.V. 1994: Desiccation and cryoprotection: overlapping adaptations. Cryo-Letters 15: 181-190.

SINENSKY M. 1974: Homeoviscous adaptation - a homeostatic process that regulates viscosity of membrane lipids in Escherichia coli. Proc. Natl. Acad. Sci. USA 71: 52-525.

SLÁMA K. 1964: Hormonal control of respiratory metabolism during growth, reproduction and diapause in female adults of Pyrrhocoris apterus L. (Hemiptera). J. Insect Physiol. 10: 283-303.

Socha R., Šlua J. \& ZemeK R. 1997: Feeding, drinking and digestive enzyme activities in long- and short-day females of Pyrrhocoris apterus (Heteroptera). Physiol. Entomol. 22: 161-169.

Sømme L. 1999: The physiology of cold hardiness in terrestrial arthropods. Eur. J. Entomol. 96: 1-10.

SøMmE L. 2000: The history of cold hardiness research in terrestrial arthropods. Cryo-Letters 21: 289-296.

Storey K.B. \& Storey J.M. 1991: Biochemistry of cryoprotectants. In: Insects at Low Temperature. Lee R.E.Jr. \& Denlinger D.L. (eds), Chapman \& Hall, New York and London, pp. 64-93.

ŠULA J., SOCHA R. \& ZEMEK R. 1998: Wing morph-related differences in adults of temperate population of Pyrrhocoris apterus (L.) (Heteroptera: Pyrrhocoridae). Comp. Biochem. Physiol. A 121: $363-373$.

Tanaka T., Ikita K., Ashida T., Motoyama Y., Yamaguchi Y. \& SATouch K. 1996: Effects of growth temperature on the fatty acid composition of the free-living nematode Caenorhabditis elegans. Lipids 31: 1173-1178.

Received September 27, 2001; revised December 5, 2001; accepted April 29, 2002 